Anuario del Instituto de Historia Argentina, vol. 17, nº 2, e051, diciembre 2017.

ISSN 2314-257X

Universidad Nacional de La Plata.

Facultad de Humanidades y Ciencias de la Educación.

Centro de Historia Argentina y Americana

\title{
El Real de San Felipe y Santiago de Montevideo (1724-1749): plaza y fuerte de los Borbones en la afirmaci ón de la conquista de la Banda Oriental
}

\author{
The Real of San Felipe and Santiago de Montevideo (1724-1749): \\ square and fort of the Bourbons in the affirmation of the conquest \\ of the Banda Oriental
}

\section{Pablo Fucé}

Consejo de Formación en Educación - Administración Nacional de Educación Pública (CFEANEP), Uruguay I hmoderna@gmail.com; pfuce.anep@gmail.com

\section{PALABRAS CLAVE}

Montevideo

Mauricio de Zabala

Banda Orienta

Siglo XVIII

\section{RESUMEN}

En este artículo se examinan las causas y modos en los que se desarrolló la fundación y establecimiento definitivo de la ciudad de Montevideo, actual capital de la República Oriental del Uruguay. Dicho proceso se concibe aquí como el primer paso de afirmación político-militar de los borbones de su centro político principal en la Banda Oriental, a partir del cual, y en una segunda etapa que ya ha sido estudiada en Uruguay (y que se desarrollará especialmente en la segunda mitad del siglo XVIII), ocurre la expansión, conquista y colonización del interior del territorio. Para explicar su formación se presentan las características salientes de la vida en la Plaza durante sus primeros años; en particular, sus dificultades de afirmación de autoridad local debido al control al que fueron sometidos por los agentes de la Monarquía instalados en Buenos Aires, ejemplificando asimismo el nuevo vínculo político que buscó unir a las élites locales con los representantes regios de la Casa de Borbón.

\section{KEYWORDS ABSTRACT}

Montevideo

This article examines the causes and ways in which the foundation and definitive establishment of the city of Montevideo, present capital of the República Oriental del Uruguay, was developed. This process is conceived here as the first step of political-military affirmation of the Bourbons of its main political center in the Banda Oriental, from which, and in a second stage that has already been studied in Uruguay (and that will be developed especially in the second half of the Eighteenth Century), the expansion, conquest and colonization of the interior of the territory occurs. To explain its formation the salient characteristics of the life in the Square during its first years are presented; in particular, their difficulties of asserting local

Banda Oriental authority due to the control they were subjected by the agents of the monarchy installed in Buenos Aires, also exemplifying the new political bond that sought to unite the local elites with the royal representatives of the House of Bourbon.

Recibido: 14 de octubre 2017 I Aceptado: 30 de noviembre de 2017 I Publicado: 15 de diciembre de 2017

Cita sugerida: Fucé, P. (2017). El Real de San Felipe y Santiago de Montevideo (1724-1749): plaza y fuerte de los Borbones en la afirmación de la conquista de la Banda Oriental. Anuario del Instituto de Historia Argentina, $17(2)$, e051. https://doi.org/10.24215/2314257Xe051 
Entre 1724 y 1749 se produjo la fundación de la ciudad de Montevideo, actual capital de la República Oriental del Uruguay, proceso que a todas luces sus autoridades imperiales y regionales acompañaron con una voluntad política diferente a la del siglo anterior. Como se sabe, luego de la Guerra de Sucesión al trono (1701-1714) comenzó un periodo de expansión demográfica y económica en Europa, acelerado a partir de la década del 60 (Enciso, 2001). En la nueva coyuntura, la corona revalorizó el frente atlántico americano (Tuñón de Lara, 1980). La conquista y colonización del Río Grande por los lusos y de la Banda Oriental y Entre Ríos por los hispanos fue parte de este fenómeno político y económico más general.

En lo que respecta específicamente al rol que jugó en este proceso la historia de Montevideo, a lo largo del periodo hispano pueden reconocerse cinco instancias importantes: (1) La fundación de esta ciudad y su afirmación política (1724-1749), (2) la expulsión de los jesuitas en 1767, (3) la campaña militar dirigida por Pedro Cevallos, que alcanzó Santa Catalina y ocupó definitivamente para España la Colonia del Sacramento, (4) el Tratado de San Ildefonso, que fijó el límite de ambos imperios (establecido desde la desembocadura del Chuy al Fuerte de San Miguel y siguiendo la Laguna Merín, y desde allí hasta las cabeceras o vertientes del Río Negro y las de los ríos que desembocan en el Río Uruguay hasta el Pepirí Guazú), y (5), el Reglamento de Libre Comercio expedido en 1778 (Millot y Bertino, 1991, p. 16)ํㅗ. En las siguientes páginas nos ocuparemos del primer tramo.

Preocupado por las consecuencias del Tratado de Utrecht, y considerando además el peligro del intento de Portugal de nuevas fundaciones en la Banda Oriental, tanto en la bahía de la que sería Montevideo como también en Maldonado, Felipe V dio instrucciones al gobernador del Río de la

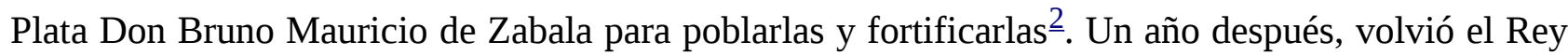
a instruirle sobre la conveniencia de instalarse en el lugar denominado Montem video, evaluando por entonces como particularmente comprometedora la ruptura de relaciones con Inglaterra que podría traer como resultado el apoderamiento inglés de la bahía (Travieso, 1923, p. 54) ${ }^{3}$.

La fundación de Colonia del Sacramento en 1680 por los portugueses no había hecho más que hacer notar a las autoridades hispanas las debilidades defensivas de este frente rioplatense, y el riesgo de la eventual pérdida de la Banda Oriental, (“tierra sin ningún provecho” hasta la introducción de la ganadería por Hernandarias en 1611 y 1617, pero cada día más relevante para la extracción de cueros y el arreo de ganados hacia Río Grande). Montevideo tenía que revertir esa situación hacia el interior del territorio, así como contribuir a vigilar e impedir el acceso libre de embarcaciones por el Río de la Plata. Primero lo hizo como un simple fuerte (el de San José, establecido en 1724), y luego ya cumplió la misión como ciudad, a partir del 24 de diciembre de 1726 (Reyes Abadie, Bruschera y Melogno, 1974, p. 30). Su Cabildo se inició el primero de enero de 1730, y esto cierra su ciclo fundacional y de primera configuración política.

En ese contexto general, el proceso montevideano se concibe en este artículo como el primer paso de afirmación político-militar de los borbones del que será su centro político principal en la Banda Oriental, a partir del cual, en una segunda etapa -que ya ha sido estudiada por parte de la historiografía uruguaya (y que se desarrolla especialmente en la segunda mitad del siglo XVIII)-, ocurre la expansión, conquista y colonización del interior de su territorio en el marco de un complejo proceso portuario rioplatense (Jumar, 2010). Para explicar la instalación de su “equipamiento político” y las "tecnologías” fundamentales que le acompañaron (Barriera, 2013, p. 97) se presentan aquí las características salientes de la vida en la Plaza durante sus primeros años; 
en particular, sus dificultades de afirmación de autoridad local debido al control al que fueron sometidos por los agentes de la Monarquía instalados en Buenos Aires, lo cual asimismo ejemplifica el nuevo vínculo político que buscaba unir a las élites locales con los representantes regios de la Casa de Borbón.

La fundación ulterior de villas y ciudades hispanas dentro y fuera de la jurisdicción de la ciudad (Rial y Klaczko, 1981), así como el intento de ampliación territorial, confirmó a partir de 1749 el logro de la conformación y preservación que había alcanzado su centro base de poder, Montevideo. A partir de entonces, los borbones estuvieron en condiciones de proporcionar a los habitantes hispano-criollos de la campaña el soporte mínimo indispensable (nunca suficiente por cierto durante el periodo hispano) para asentar un control político que mantuviera las condiciones para la explotación ganadera.

Antes de la fundación de Montevideo eran los franceses quienes más frecuentaban la región, al aprovechar el ascenso del Borbón a la Corona de España e Indias. En 1720, cuatro navíos al mando del capitán Esteban Moreau fondearon en la costa de Maldonado, desembarcaron e iniciaron la corambre, principal actividad económica del momento. Enterado de la situación, Zabala envió al capitán Martín José de Echauri a expulsarlos, pero sólo logró que se replegaran al paraje de Castillos, donde levantaron campamento y enviaron dos barcos a la bahía Montevideo con el objetivo de retomar sus operaciones comerciales. Sin embargo, esta vez las tropas al mando del capitán Antonio Pando los derrotaron, y fue herido de muerte el propio capitán Moreau. En nueva real cédula enviada al gobernador Zabala, el rey Felipe $\mathrm{V}$ le ordenó enfáticamente levantar fortificaciones en Maldonado y Montevideo.

El 30 de julio de 1722 el Cabildo de Buenos Aires registró haber resuelto que el paraje conocido como Montevideo sería asiento de una nueva población, pero las acciones de implementación efectiva otra vez se demoraron. La dilación en la ejecución de los planes llevó nuevamente a Felipe $\mathrm{V}$ a expedir carta a Zabala, advirtiéndole que en caso de no haber iniciado las fortificaciones en los dos parajes señalados debía hacerlo de inmediato, antes de que los portugueses ocuparan estos sitios definitivamente y tornaran más difícil el establecimiento español en la Banda Oriental.

Los lusitanos, en cambio, no se detenían. El 29 de junio de 1723 el rey de Portugal, Juan V, retomó el proyecto de instalación en la bahía de Montevideo. Contaba con el respaldo de la Colonia del Sacramento que, por entonces, requería de la fundación de otra ciudad cercana de apoyo para asentar el dominio lusitano en la Banda Oriental. Pronto, el gobernador de Río de Janeiro Ayres de Saldaña recibió la orden del rey y se aprestó a enviar hombres a la bahía que más tarde sería Montevideo. Efectivamente, el 22 de noviembre de ese año, el maestre de campo Manuel Freitas da Fonseca comandó una expedición de 250 hombres con víveres para seis meses. La expedición contaba con tres barcos al mando del capitán Manuel Henriques Noronha, acompañados de dos embarcaciones menores. Luego del desembarco instalaron dieciocho tiendas de campaña e iniciaron la rápida construcción de un fuerte en el vértice de la península (Azarola Gil, 1976)ํ.

El primer día de diciembre de 1723, Zabala, enterado por el práctico del Río de la Plata Pedro Gronardo de la llegada de los portugueses a ese punto, decidió proceder al desalojo lusitano. Tres días después convirtió la Guardia de San Juan —a cuatro leguas al norte de la Colonia del 
Sacramento- en núcleo de operaciones militares, las que rápidamente se sucedieron. El siete de diciembre los españoles dejaron sin caballos ni ganados a los portugueses. El capitán al mando de la acción fue Alonso de la Vega, quien contó con un destacamento de caballería que se posicionó frente al sitio en que se encontraba el campamento de Freitas da Fonseca.

Felipe V, en tanto, volvió a advertir a Zabala que -en caso de continuar omiso- cumpliera las órdenes reales de inmediato, so pena de acusación de gravísimo cargo. Zabala se encontraba por entonces exigiendo la rendición del campamento de Freitas da Fonseca y de la Colonia del Sacramento. Por fin, el 19 de enero de 1724 Freitas da Fonseca abandonó el lugar, y regresó a Río de Janeiro. De esta manera finalizó el proyecto lusitano de establecerse en la bahía de Montevideo, pero no cesaron sus incursiones por la campaña de la Banda Oriental.

A lo largo del periodo hispano, la lucha entre imperios traería consigo enormes inconvenientes militares y diplomáticos a los centros políticos de Montevideo, Buenos Aires y Madrid (Arteaga, 1999). Por esa razón, la Banda Oriental se ha definido con razón como una frontera "abierta” y móvil (Reyes Abadie, Bruschera y Melogno, 1974, p. 19). Por un lado, tenía un frente terrestre de rivalidad luso-española, por otro, el problema interno provocado por las tensiones y conflictos entre hispanos con poblaciones nativas y mano de obra estacional y, finalmente, la Banda Oriental contaba con un frente marítimo sobre el Río de la Plata y parte del Atlántico (Martínez Montero, 1977). En este escenario, el enclave fue convirtiéndose en núcleo de vigilancia y control del Río de la Plata y el Atlántico sur, hasta llegar a ser sede del Apostadero Naval, entre otros privilegios relacionados.

El 20 de enero de 1724 las tropas españolas ingresaron a la península del paraje conocido ya en todo el imperio como Montem Video. A este episodio siguió la rápida erección del Fuerte San José 5 y las murallas (Baroffio Burastero, 1994). Por orden de Zabala, el ingeniero Domingo Petrarca procedió desde febrero de 1724 a iniciar las fortificaciones, dividir la extensión de la península y delinear las primeras manzanas alrededor de un eje central que serviría de plaza mayor.

Petrarca delineó las calles en relación con la curva solar, de modo que, aun a mediodía, una de las aceras recibiera sombra. Erigida por motivos militares, resultaba fundamental dotar a la ciudad de fortificaciones adecuadas para cumplir los objetivos asignados, entre ellos y fundamental, la protección de la élite político-militar que allí residía o concertaba negocios. Sin perjuicios de otras funciones, Montevideo nunca abandonó durante la Monarquía la función de fuerte; la Plaza fue asentamiento militar desde el comienzo, pieza de la conquista de la Banda Oriental, hecho que se evidenció a partir del trazado urbano, cuya forma -con la plaza de armas en lugar destacado- daba cuenta de su función estratégica y militar.

El tres de julio de 1725, don Francisco de Alzáibar obtuvo un contrato con el rey comprometiéndose a conducir, a costa suya, a familias procedentes de las islas Canarias con el propósito de poblar la ciudad. Además, ofreció cuatrocientos hombres de tropa para su defensa (de la Torre, Sala de Touron y Rodríguez, 1967) $\underline{6}$. El cuatro de agosto del mismo año, el Marqués de Valhermoso, gobernador de Canarias, dio inicio a la tarea de reclutamiento de veinticinco familias para poblar Montevideo (Azarola, 1976). El 28 de agosto de 1726 Zabala dictó el auto de erección de la ciudad de San Felipe y Santiago de Montevideo, dirigido al Cabildo de Buenos Aires, y declaró que 
correspondía a las familias y sus descendientes legítimos que se trasladaran a Montevideo a poblar recibir el título de hijosdalgo de solar conocido. Luego de una travesía por el Atlántico de 90 días arribó a Montevideo el 19 de noviembre de 1726 el primer grupo de familias canarias en el navío Nuestra Señora de la Encina. Al día siguiente, Zabala abrió el padrón para asentar en él las familias pobladoras. El gobernador delegó en Pedro Millán la realización de esta tarea que comenzó el 20 de diciembre de 1726 y continuó en actas sucesivas, conforme llegaban los nuevos pobladores, hasta el 20 de diciembre de 1728. El proceso fundacional no se detuvo, y el primero de enero de $1730^{7}$ se instaló el Cabildo, fecha de “fundación jurídica” de la ciudad (Petit Muñoz, Narancio y Traibel, 1947, p. 39).

El 24 de diciembre de 1726, Pedro Millán, Capitán de Corazas, comenzó el reparto de solares y chacras $^{8}$, que se extendió por varios años. Millán también fijó la jurisdicción de la ciudad, es decir, el territorio que comprendería la autoridad del futuro Cabildo, y en cuyo predio los nuevos vecinos tendrían tierras para las faenas de campo y monte (véase mapa adjunto).

Los límites determinados para la jurisdicción de Montevideo fueron los siguientes (Assunçao y Bombet Franco, p. 17)ํㅗㄹ desde la boca del arroyo Cufré siguiendo la costa del Río de la Plata hasta alcanzar el puerto de la ciudad, y desde este punto y siguiendo la costa del mar hasta llegar a las sierras de Maldonado. Se estableció el cerro Pan de Azúcar como mojón del frente, y las cabeceras de los ríos San José y Santa Lucía como mojones del fondo, éstos remataban en un

....albardón que sirve de camino a los faeneros de corambres, y atraviesa la tierra desde la misma sierra y paraje que llaman de Cebollatí, y viene a rematar este dicho albardón a los cerros que llaman Guejonmi (Ojosmí u Ojolmí) y divide las vertientes de los dichos ríos San José y Santa Lucía, en esta parte del sur, y las que corren hacia la parte del norte y componen el río de Yí, y corren a los campos del Río Negro, y con esta seña del dicho albardón que divide las vertientes a norte y sur, y ha de servir de mojón por la parte del fondo, queda deslindado el término y jurisdicción que señalo a esta ciudad (véase mapa) ${ }^{10}$.

La jurisdicción se extendía ciento cincuenta kilómetros de norte a sur, y doscientos de este a oeste, abarcando los actuales departamentos uruguayos de Montevideo, Canelones, San José, y parte de los departamentos de Maldonado, Lavalleja, Florida y Flores. Fuera de ella estaba la jurisdicción del gobierno de Buenos Aires, y al norte, en la confluencia del río Uruguay con el río Negro, el

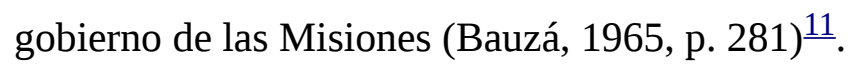

El 12 de marzo de 1727 fue delimitado el ejido de la ciudad y empezó la adjudicación de chacras, con la toma de los predios situados sobre el arroyo Miguelete $\underline{\underline{12}}$. Las medidas de estas chacras iban de 200 a 400 varas, que “debían entenderse como frentes a la costa y barranca del Miguelete”; todas tenían una legua de largo “a los rumbos que le pertenezcan” (Azarola Gil, 1976, p. 131). A los poseedores se les imponía la condición de comenzar las tareas agrícolas de inmediato, y contaban con el plazo de tres meses desde el momento de la aprobación de Zabala para edificar su vivienda y labrar la tierra para sementeras y plantíos. En 1728, Millán dio cumplimiento a la distribución de estancias y se delimitaron 22 fracciones, todas de tres mil varas de frente y una legua y media de 
fondo. Veinte estancias estaban en las inmediaciones del arroyo Pando, y las restantes en el que con posterioridad fuera nombrado arroyo Carrasco (Barrios Pintos, 1973, p. 76).

La agricultura se fue desarrollando en los alrededores de Montevideo en torno al cultivo de trigo y árboles frutales combinados con la cría de aves de corral, cerdos y ganado lechero (Pérez Castellano, 1968) $\underline{13}$. Aunque muy reducida y de escaso desarrollo técnico cobró especial interés a partir del año 1778, en que aumentó el consumo como resultado del incremento de la población estable y la llegada de un mayor número de barcos mercantes que recalaban en la bahía. El núcleo de agricultores inicial más importante provino de las concesiones de tierras sobre los arroyos Miguelete, Pantanoso y Carrasco, a las que siguieron concesiones en los parajes de Las Brujas, Las Piedras, Canelón Chico, Pando y Toledo, entre otros. En cambio, después de 1778 la situación fue otra, y los beneficios del vecindario estuvieron ante todo en la explotación ganadera, por lo que ocurrió entre los agricultores una marcada diferenciación de condiciones (Real de Azúa, 1961), que tuvo enorme impacto social $\frac{14}{}$.

El 15 de enero de 1727 se fijaron las celebraciones de la ciudad, ampliadas por el Cabildo en sus primeros acuerdos de 1730. Ellas constituyeron parte de la matriz de la trama simbólica (Rama, 1998), litúrgica y ceremonial de autoridades y pobladores, destinada a formar las imágenes virtuosas de las figuras tutelares que en su orden jerárquico terrenal y sobrenatural orientaban la vida política de la ciudad y su jurisdicción (Fucé, 2014)ํㅗㄹㅡ. Entre las principales se contaban $\underline{16}$ : ceremonia a los Santos Patronos de la ciudad, San Felipe y Santiago (víspera y primero de mayo, fecha que debía salir el estandarte real), ceremonia de la Concepción de Nuestra Señora (ocho de diciembre), titular de la iglesia Matriz y el día del Señor San Sebastián (20 de enero), en memoria del día que llegaron a la ensenada las tropas del rey. Los días “de tabla” agregados por el Cabildo el 30 de enero de 1730 a los anteriores, y en los que debía mostrarse junto a las autoridades eclesiásticas, fueron: el primer día de enero de cada año; el día de "Nuestra Señora de la Candelaria” (2 de febrero); los miércoles de Ceniza; los oficios de Semana Santa; primer día de cuaresma; primer día de Pascua de Resurrección, primer día de Pascua del Espíritu Santo; día de la “Asunción de Nuestra Señora” (15 de agosto); víspera y día de Pascua de Navidad; víspera y día de Corpus y su octava, y el 19 de diciembre, natalicio del rey Felipe V (Apolant, 1975, p. 126).

El 27 de marzo de 1729 arribó al puerto (en el “San Martín” de Alzáibar), el segundo núcleo poblacional de colonos canarios. La demora de casi tres años de unas 25 familias que totalizaban entre 130 y 136 personas se debió a la guerra entre España e Inglaterra. Como se apuntó, el primer día de enero de 1730 se constituyó el Cabildo, y el gobernador Bruno Mauricio de Zabala nombró y dio posesión de cargos a los regidores en solemne ceremonia.

El 30 de enero de 1730 se reunió por primera vez el cuerpo capitular en presencia de Zabala. Y el 30 de mayo, el Ayuntamiento fijó la nomenclatura de las calles, tomando como base los nombres ya dados por la costumbre de los vecinos (véase plano adjunto): calle Real (actual Rincón), de la Frontera (actual Piedras), de la Carrera (Sarandí), de Callo (actual Misiones), de la Fuente (actual Cerrito), de la Cruz (25 de Mayo), del Piquete (actual Buenos Aires), Traviesa (actual Zabala), del Puerto Chico (Treinta y Tres), de Afuera (Reconquista), de la Iglesia (Ituzaingó), del Medio (Juan Carlos Gómez), Entera (Bartolomé Mitre) ${ }^{\frac{17}{2}}$. Cuando se completó la muralla, la planta edificada de 


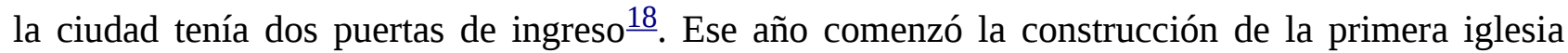
Matriz que tuvo "hasta cinco varas de altura", erigida parcialmente con el esfuerzo de los primeros vecinos "en medio de la suma pobreza en que se hallaban", hasta que, en octubre de 1738, el capitán de mar y guerra Francisco de Alzáibar se obligó a concluirla enteramente a su costa $\underline{19}$, cosa que hizo en $1740^{\underline{20}}$-luego se colocó el techo de tejas en $1760^{\underline{21}}$ - Entre 1785 y 1790 hubo derrumbes parciales pero importantes que pusieron en riesgo la integridad física de los fieles, por lo que se debió entonces -por determinación del cura vicario, el Cabildo y el gobernador en 1788realizar el culto en la capilla de los jesuitas que habían sido expulsados por decisión del rey $\underline{22}$. Recién el 21 de octubre de 1804 se inauguró con misa solemne el nuevo edificio $\underline{23}$.

En los primeros años de la ciudad, dada la imposibilidad efectiva de atender debidamente las estancias por la resistencia indígena (Acosta y Lara, 1989), con solares y tierras de mejor calidad distribuidos por los comandantes a sus propios oficiales, y con los obstáculos impuestos por las autoridades bonaerenses para la exportación, los vecinos fueron en su gran mayoría labradores de pequeños y medianos predios, y las estancias escasa o nulamente atendidas $\underline{24}$. En estos años, la impronta de su dependencia militar e institucional con relación al cuerpo militar asentado en Buenos Aires fue determinante en la conformación política de la élite local, tanto en su lealtad al régimen como en la exaltación de los principios jerárquicos y organicistas de la monarquía, hecho que ayuda a entender, más allá de vacilaciones, su fidelidad sostenida hasta 1814 (Aguerre, 2012).

Por su parte, frente a la ocupación de campos que asomaba permanente los indígenas defendieron sus tierras, negociando y también haciendo la guerra $\underline{25}$. En la lucha contra los españoles se opusieron con tenacidad a la fundación de Montevideo (Acosta y Lara, 1989) y, como se advierte en las actas capitulares de los treinta primeros años, permanecieron la mayor parte del tiempo en estado de guerra, practicando en los momentos más duros del conflicto —si no todos ellos, sí al menos algunas de sus parcialidades - la extracción de ganado de las estancias, el incendio de sus cascos y el robo de mujeres (Bracco, 2004). En 1730 los minuanes atacaron la estancia y casa del alcalde de primer voto del Ayuntamiento montevideano, y en 1731 intentaron asaltar la ciudad. La ceremonia de paz de 1732 con los minuanes, dirigida por Zabala, abrió un periodo de tensa calma que se prolongó, no sin dificultades, hasta 1750-1752 (Fucé, 2014)를.

Otro ejemplo del sello de control impuesto por Zabala y sus continuadores a los colonos recientemente establecidos en Montevideo fue el peso avasallante que dieron a las autoridades enviadas desde Buenos Aires, muestra de la inspección y subordinación que esperaban los oficiales de la monarquía en esta nueva etapa dinástica. Como Plaza Militar, la ciudad estuvo bajo la autoridad de comandantes dependientes del gobierno y capitanía general de Buenos Aires. De 1726 a 1751 hubo nueve comandantes militares $\underline{27}$.

La difícil situación de los primeros años de Montevideo provocó roces en el Cabildo. El Ayuntamiento, formado entonces por hombres sencillos y emprendedores (en su mayor número pobladores que habían llegado en busca de oportunidades a una tierra ignota y que, una vez en ella, debían alternar el negocio y ocupaciones familiares con las obligaciones impuestas para la defensa de la ciudad y el ejercicio de los empleos públicos), careció del brillo y linaje que los comandantes 
militares (y luego los gobernadores) ostentaban a menudo. Por eso, el conflicto se presentó inevitable y marcó la tónica de la relación política, mayormente tensa, entre ambas figuras centrales de la ciudad.

El dominio político y la vigilancia del puerto recaían en los comandantes, hombres con instrucción y de paso, respetados por su función prioritariamente defensiva, conocedores de los problemas a una escala más amplia que la de Montevideo. Jugó por cierto en esta relación desigual que el arrojo del vecindario fue mérito necesario pero no suficiente para imponer el orden político que tocaba a la corporación capitular en la administración de justicia, vigilancia de las leyes y cumplimiento de ordenanzas. En la recién establecida sede de la república cristiana de la Banda Oriental, y en oportunidades cruciales de su historia, los vecinos de Montevideo carecieron del conocimiento político necesario para articular satisfactoriamente a través del Cabildo —única institución que les resultaba accesible - muchas de las demandas que el régimen requería para asegurar el orden interno y la defensa fronteriza con el Brasil portugués, circunstancia que al menos hasta el último cuarto del siglo XVIII fue aprovechada por los mandos superiores.

En las primeras décadas del siglo, los comandantes se excedieron en sus competencias invocando su autoridad de jefes de la Guarnición y responsables del orden político. La vida cotidiana de Montevideo se conformó en la rutina de un régimen militar, que aunque incapaz de garantizar plenamente la seguridad de vidas y posesiones de los súbditos supo -a través de la exaltación de atributos de la figura del monarca y la alianza con la élite local, beneficiada con crecientes privilegios territoriales y comerciales- mantener sólidas alianzas de interés. Como bien lo ha dicho Pablo Blanco: por esos años "la vida impregnóse con las costumbres de cuartel”, no habiendo "ceremonia ni fiesta pública, motivo de algazara o de duelo, en que la clase militar no tomase participación principal” (Blanco Acevedo, 1959, p. 94).

En Montevideo y su jurisdicción, los valores del orden absolutista estuvieron asentados en esta concepción de la vida, señorial, jerárquica y brutal (Barrán, 2008), que se buscó inculcar en la práctica cotidiana del poder local. El cronista Isidoro de María apuntó con claridad que bajo la dominación hispana la vida de Montevideo estaba pautada por el disparo del cañón, realizado al amanecer (por el buque designado una vez que se instaló el apostadero naval), a la puesta del sol y a las ocho de la noche. Ocurrido el disparo, el oficial mayor de la plaza abría o cerraba los portones de la ciudad, cuyas llaves se resguardaban en el Fuerte; lo mismo ocurría con las llaves de la puerta de la ciudadela, el Cabildo, el Fuerte de San José y el Fuerte de gobierno (De María, 2005, p. $117)^{\underline{28}}$. Hubo, pues, un verdadero ritmo y culto a las acciones militares borbónicas, que afirmaban el dominio real en la ciudad y su jurisdicción.

Por medio de ordenanzas, Zabala había determinado los cometidos de los comandantes de Montevideo. Les había permitido participar de las deliberaciones del Ayuntamiento, pero despojados de su investidura militar y con vara de justicia. La entrada al Cabildo les estaba restringida, y podían ingresar en caso de ser llamados por el Ayuntamiento o tener algo que proponer al mismo. Debían asimismo, durante las sesiones, únicamente velar por el mantenimiento del orden en los debates, y justificar las celebraciones de sus reuniones.

El conflicto se manifestó tan pronto los comandantes quisieron someter a todas sus órdenes a los 
vecinos recién establecidos que participaban de la gestión capitular (Blanco Acevedo, 1959, p. 44). Frente a las presiones y falta de apoyo a iniciativas del Ayuntamiento, los regidores propusieron al gobernador de Buenos Aires, José de Andonaegui, el nombramiento de un teniente de rey para que manejara el mando político al modo y conformidad que los gobernadores de las ciudades de Santa Fe y San Juan de Vera de las Siete Corrientes $\underline{29}$. El nombramiento recayó al fin en el capitán Francisco Gorriti, quien no aceptó el empleo. El primer teniente de rey fue don Juan de Achucarro $\underline{\underline{30}}$, alcalde de primer voto en el año 1744, impuesto por el gobernador Andonaegui, a pesar de que el Cabildo había protestado no sobre su idoneidad sino por el hecho que Achucarro acumulaba en su persona varias comisiones y empleos que requerían afianzamiento. Entendía el Cabildo que las fianzas quedarían anuladas al asumir el afianzado la autoridad de teniente de rey, pero Andonaegui se mantuvo firme hasta 1750 en que Achucarro dimitió $\underline{\underline{31}}$. En 1757 don Juan de Achucarro fue nombrado teniente gobernador y justicia mayor de la ciudadela de Montevideo ${ }^{32}$.

Sin embargo, y en medio de estas dificultades y conflictos, es de subrayar que, en su gran mayoría, los jóvenes y rústicos integrantes de los primeros cabildos estuvieron dispuestos a aprender las competencias de sus nuevos empleos, y atendieron todo lo más eficazmente que les fue posible a la afirmación del gobierno local, el desarrollo urbanístico de la ciudad, el progreso económico del vecindario y la lealtad a la Corona.

Sin desconocer la existencia de polémicas, e incluso altercados entre miembros de la Corporación, resulta claro que esas mismas dificultades de asentamiento unieron a los pobladores en torno al Cabildo. Obediencia y lealtad fueron centro de sus preocupaciones políticas, como lo confirman los oficios intercambiados por las autoridades locales, sus "bandos de buen gobierno", las notas testimoniadas, las actas de la Corporación y el cuidadoso énfasis dispuesto en la organización y desarrollo de las ceremonias y sus contenidos políticos. El gobierno de la ciudad ejercido por el Cabildo no fue sólo administración y cumplimiento de obligaciones impuestas por la monarquía. En la trama político-institucional del orden jerárquico confesional español, el Ayuntamiento hizo que la urbe se transformara efectivamente en ciudad, es decir, en un modo de vivir que formalizaba las relaciones sociales y el poder político dominante de múltiples maneras, entre las que se contaban, y no en menor medida, las ceremonias de exaltación al régimen.

Conforme avanzó el siglo XVIII, a las acciones políticas del incipiente órgano de gobierno local se sumó con más fuerza el discurso de fidelidad de la monárquica borbónica (Ribeiro, 2013), sedienta de observancia de sus reales cédulas por los gobernantes locales de Montevideo, instalados en un territorio lejano y periférico pero cada vez más relevante en sus objetivos políticos y económicos regionales e internacionales, tal y como lo prueba el nudo de intereses en torno a la Colonia del Sacramento (Tellez Alarcia, 2006).

La reiteración de comunicaciones al público de los más variados y detallados sucesos de la corte, efectuada desde las ceremonias del Ayuntamiento, y bajo estricta vigilancia de los gobernadores, fue uno de los muchos ejemplos del firme propósito de afirmación de su presencia en el gobierno de Montevideo. Y por si todo ello fuera poco, la prédica del estamento militar al respeto de las jerarquías constitutivas del régimen (desarrollada por comandantes primero, y gobernadores y oficiales del Apostadero Naval después) también contribuyó a afirmar en los vasallos la idea de 
fidelidad a la Monarquía como “un valor de peso en tiempos de lealtades dudosas” (Barriera, 2006, p. 126) ${ }^{33}$. Fuera de la rutina del puerto y los ejercicios militares en la plaza de armas y el campo de Marte (Pérez Montero, 1964, p. 195), las ceremonias resaltaron en tiempo y modo extraordinario el vínculo político de Montevideo con la Monarquía, y de manera más general, y no menos notable, con el orden sociopolítico que ella defendía y representaba.

Si esos fueron rasgos de continuidad, hubo otros en cambio que hicieron de Montevideo una ciudad que vivió importantes transformaciones a lo largo del siglo XVIII y comienzos del siglo XIX (Pivel Devoto, 1946). De los 250 habitantes que tenía registrados en 1730 pasó en 1757 a 1.667 habitantes con 170 casas habitación. En 1769 el número de habitantes se elevó a 8.602 distribuidos del siguiente modo: en el recinto y sus alrededores, 4.174, y dentro de la jurisdicción 4.528 habitantes. Censados por el alcalde de primer voto en 1778 se encontraron 4.270 habitantes y 920 casas, en tanto en la jurisdicción había 5.088 habitantes y 1.237 casas. En conjunto totalizaban en esa fecha 9.358 habitantes y 2.157 casas que pueden discriminarse de la siguiente manera: 6.695 españoles y criollos, 1.386 esclavos, 562 negros libres, 538 “pardos libres” y 177 indígenas (Bresciano, 1977, p. 26) ${ }^{\frac{34}{}}$. En un informe del Cabildo, a propósito de la necesidad de incrementar el número de iglesias en Montevideo, se señaló en mayo de 1780 que en los últimos años se había producido un “increíble” aumento de la población que estimaba para el recinto edificado y sus alrededores en 9.000 “y más almas”프.

Para comienzos del siglo XIX Francisco Bauzá estimó que la población estable de la Banda Oriental era de poco más de 40.000 habitantes, de los cuales unos 15.000 se albergaban en Montevideo (BAUZÁ, 1965, p. 325). Este crecimiento de la población montevideana debe inscribirse en cambio, en una realidad demográfica en la que la presencia humana era rara, “infrecuente en el paisaje”, según expresión de José Pedro Barrán, quien señaló además que en 1800 había en el territorio de lo que luego sería el Uruguay unos 20 o 30 mil habitantes, es decir, una densidad que no llegaba ni siquiera a un habitante y medio por km cuadrado (Barrán, 2008, p. 17). De las ciudades al sur de la Banda Oriental, Montevideo fue la de mayor concentración de personas, y por tanto, el escenario de las más intensas, frecuentes y múltiples interacciones cara a cara.

Al igual que las Plazas fuertes del Callao o Cartagena de Indias, un objetivo del Real de Montevideo fue prevenir los ataques que por la vía fluvial del Plata se podían efectuar al Reino de Indias, y en él al Virreinato del Perú, creado en 1534. La ubicación geográfica de la nueva y tardía ciudad, en la entrada al Río de la Plata, y la excelencia de su puerto natural de la bahía (reconocido por pobladores, viajeros y navegantes de la época por su ubicación en las costas cercanas al canal de acceso, abrigo de los vientos y aguas profundas que permitían el desembarco sin trasbordos) pronto demostró a la Monarquía la conveniencia de reforzar la lealtad de los vasallos de Montevideo. Hecho que se confirma ya con la real orden de 22 de diciembre de 1749, por la cual la Monarquía creó la Gobernación política y militar de Montevideo y su jurisdicción, lo que parcialmente satisfizo una de las primeras solicitudes de los vecinos $\underline{36}$. 


\section{Mapas y planos}

MAPA I. ASENTAMIENTOS URBANOS EN LA BANDA ORIENTAL EN LA EPOCA COLONIAL

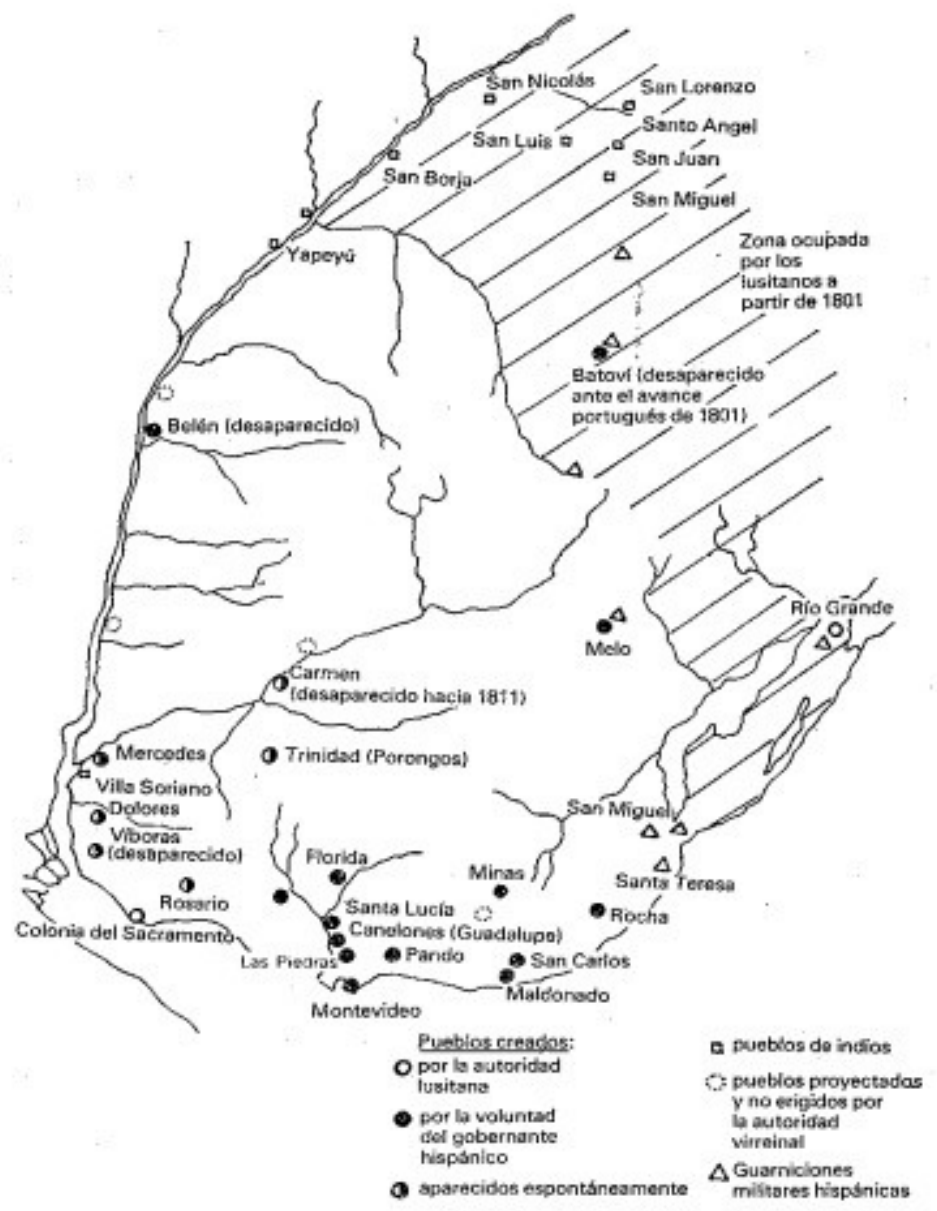

(Tomado de Juan Rial y Jaime Klaczko, p. 19) 
MAPA II. Centros poblados del. rio de la plata en la epoca COLONIAL

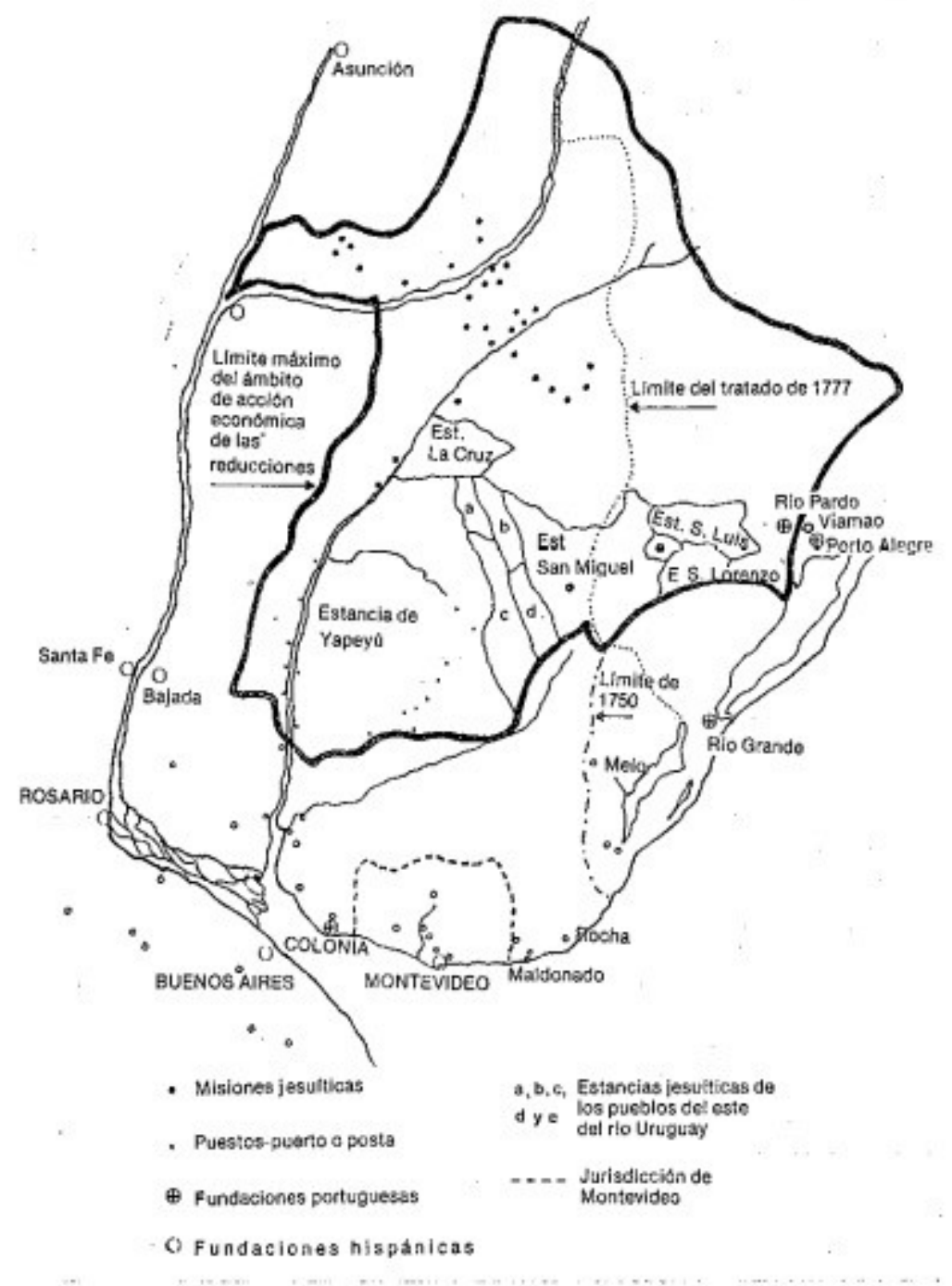

(Tomado de Juan Rial y Jaime Klaczko, p. 23) 


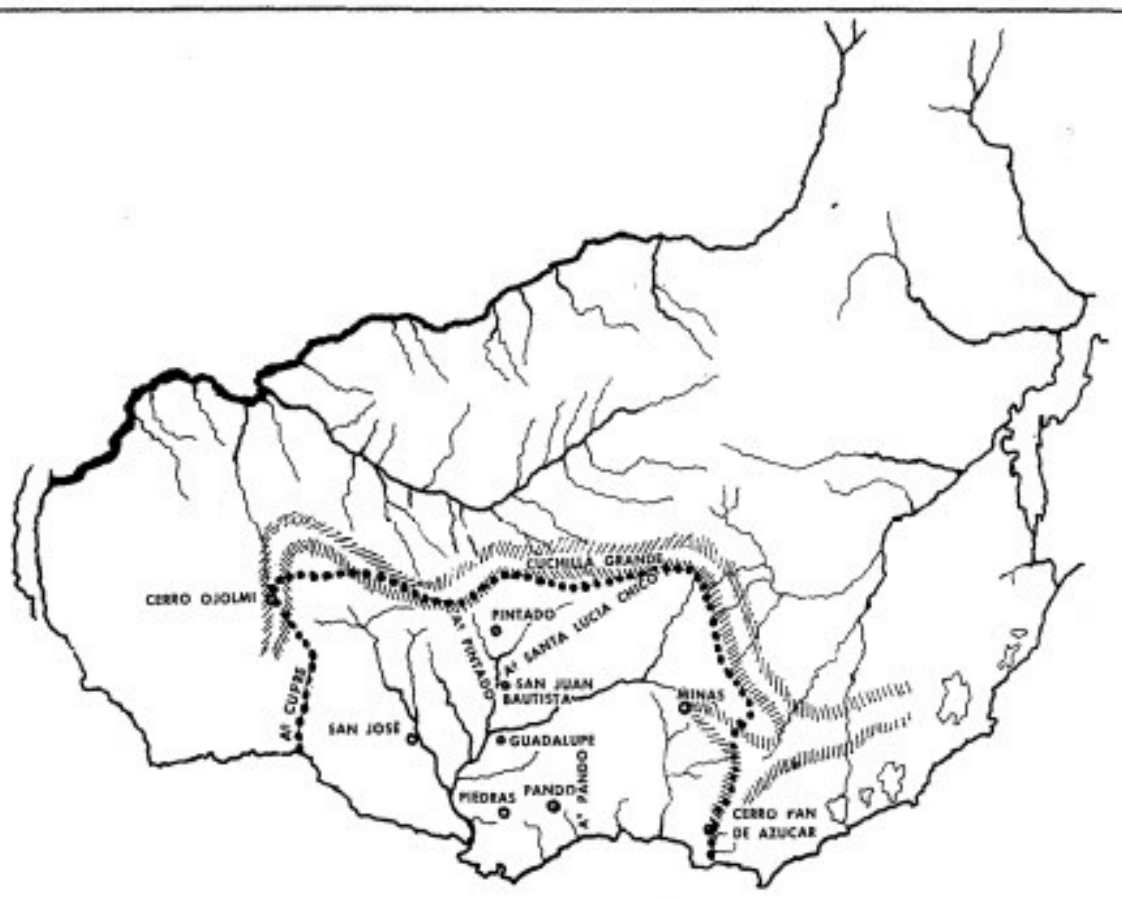

La jurisdicción de Montevideo: La costa del Rio de la Plata desde la desembocadura del arroyo Cufré hasta las sierras de Maldonado y al norte la Cuchilla Grande o albardón que sirve de camino a los faeneros de corambre $y$ que divide las vertientes de los rios San José y Santa Lueía de las que corren a la parte norte.

(Tomado de Aurora Capillas de Castellanos, p. 4) 


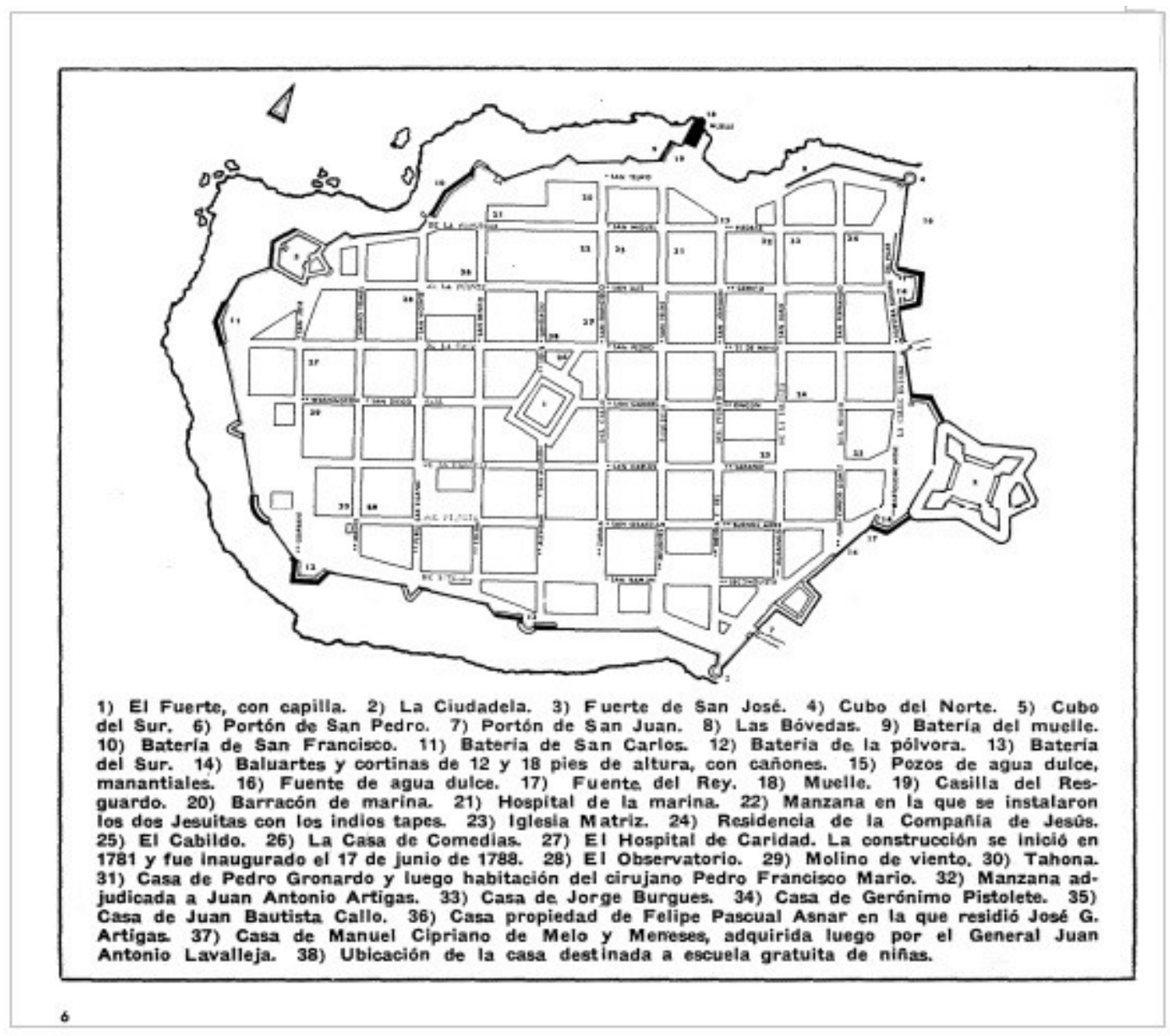

(Tomado de Aurora Capillas de Castellanos, p. 6)

\section{Notas}

1 En cuanto a lo límites, los lusitanos siguieron avanzando: en 1801 llegaron hasta el Río Ibicuy y por el este hasta el Río Yaguarón, y en 1804 ya se encontraban ocupando el Cuareim. En este proceso de expansión influyó el descubrimiento de oro en Minas Gerais, con el consiguiente cambio del centro económico del noreste hacia el centro del Brasil. Las tierras ganaderas al sur de San Pablo se valorizaron y amplias zonas comenzaron a poblarse para satisfacer la demanda de carne para la alimentación de los mineros y la necesidad de mulas para la extracción y transporte. Con el fin de obtener ganado para las estancias del sur brasilero se practicaron arreos de ganado desde la Banda Oriental.

$\underline{2}$ El 7/12/1715 el gobernador de Buenos Aires García Ros envío una carta a Felipe V explicando las peligrosas consecuencias que podían derivar de la entrega de Colonia del Sacramento. Comprendiendo la gravedad del asunto, el monarca mandó al brigadier Bruno Mauricio de Zabala con instrucciones para afirmar el dominio español en la Banda Oriental. Entre lo ordenado estaba poblar y fortificar dos parajes, el de Maldonado y Montevideo, contener a los pobladores de Colonia en los límites fijados en el Tratado, impedir el contrabando y vigilar a los indígenas, de quienes resaltaba su "celo al real servicio” en los combates de 1680, 1698 y 1705, en todos los 
cuales habían demostrado que "manejan las armas y caballos con tanta destreza, orden y disciplina militar, que podían competir y disputarlas con cualquier enemigo” de España e Indias. Revista Histórica, tomo III, año II, septiembre de 1910, núm. 7, Montevideo, Archivo Histórico Nacional, pp. 82-102.

3 La palabra Montevideo proviene de la exclamación de uno de los nautas que arribó al Río de la Plata (por entonces Río de Solís), en la nao Trinidad, que con rumbo a las Molucas comandaba Magallanes. Probablemente la expresión haya sido dicha entre el 12 y 13 de enero de 1520, más bien el 13 “a las primeras luces del día” por uno de los vigías. El término no deriva, agrega el mismo historiador, ni de Monte vi, ni de Monte vide, ni de Monte vidi, ni de Monte veo, ni de Monte vide eu: "no debe su origen al castellano, ni al portugués, ni al gallego. El nombre de Montevideo deriva del latín [...], de la expresión latina Montem video, que quiere decir cabalmente 'Veo un monte”, p. 19.

4 Los planes lusitanos de establecerse en Montevideo de forma permanente databan de 1702. La cesión de Colonia en el tratado de Utrecht dio nuevo impulso al proyecto. En real cédula de 29/6/1723, el rey Juan V impartió órdenes de fortificar Montevideo al gobernador de Río de Janeiro, Ayres de Saldanha y Albuquerque (1719-1725). Luego de superar dificultades presupuestarias el gobernador organizó una expedición al mando del maestre de campo Manuel de Freitas da Fonseca, y además pidió la colaboración del gobernador de Colonia del Sacramento, Antonio Pedro de Vasconcellos (1722-1749). La expedición fondeó la bahía el 22/11/1723, levantó campamento e inició unas primeras fortificaciones.

$\underline{5}$ Esta batería baja de tierra y fajina estaba armada con seis cañones en el ángulo formado por las actuales calles Cerrito, Piedras, Guaraní y la costa de la bahía, se construyó entre 1724 y 1741 . En 1746 se le hicieron modificaciones: se la rodeó de muros de piedra y agregaron 30 cañones. También recibió desde entonces el nombre de Fuerte de San José. La construcción fue demolida en 1880.

$\underline{6}$ En pocos años Francisco de Alzáibar se transformó en un verdadero monopolista del comercio exterior. En 1732 obtuvo un extenso e importante rincón ubicado en el oeste de la jurisdicción de Montevideo. Fue poseedor de una gran fortuna en España, introductor de las familias de colonos canarios, como se ha dicho, partícipe con sus barcos del bloqueo a la Colonia del Sacramento en 1735; fue además caballero de la Orden de Santiago, capitán de navío de la Real Armada y alguacil mayor de la Inquisición. Se ha calculado que era dueño de 12 de las 16 mil cabezas de ganado de la jurisdicción de la ciudad. Entre sus actividades se contó la compra de cueros y sebos al vecindario que intentaba eludirle haciendo contrabando, además de la apropiación de tierras y ganados por medio de la Real Instrucción de 1754. En 1766 denunció tierras que se extendían desde los límites norte de sus estancias por el sur del Río Negro hasta sus fuentes, comprendiendo así centenares de leguas. Don Alzáibar casó a su sobrina con el primer gobernador de Montevideo, mariscal Joaquín de Viana, para quien gestionó el empleo. El gobernador Viana y su esposa "la mariscala" consiguieron enormes extensiones de tierras al este de la jurisdicción sin oposición del Cabildo. El desenfado de Alzáibar le llevó a sostener que al no marcar sus ganados le pertenecían todos los que no tuvieran marcas. Expulsados los jesuitas intentó quedarse con sus inmensas extensiones territoriales, pero no lo consiguió por la oposición del vecindario que se presentó ante la Corona 
para impedirlo. Las estancias de los jesuitas se extendían desde el Alto Uruguay hasta el Río Negro, en tanto en el sur eran dueños de la Calera, una hacienda en el sudoeste, en Soriano, de la estancia de la Virgen y de la denominada Nuestra Señora de los Desamparados en el norte del Río Santa Lucía. Fue entre Alzáibar y la Compañía de Jesús que se monopolizaba en la primera mitad del siglo XVIII la mayoría de tierras y ganados. En el censo de ganado vacuno existente en la jurisdicción de Montevideo, realizado el 8/11/1753, son muy pocos los vecinos que aparecen con más de mil cabezas, pero Alzáibar, en cambio, figura con 40.000. Archivo Artigas - Comisión Nacional Archivo Artigas (AA-CNAA). Primera sección, documento 9, tomo 1, Montevideo, impresores A. Monteverde y Cía., MCML, pp. 31-32. Otros estancieros importantes fueron Francisco García de Zúñiga, cuya estancia en la Calera sobre el Río Santa Lucía cubría una extensión de 500.000 cuadras cuadradas, y Miguel Ignacio de la Cuadra quien tuvo tierras comprendidas entre los Arroyos Grande de los Porongos y el Río Yí. José Ramírez y Pérez, rico comerciante de Montevideo, complementaba sus negocios con la actividad ganadera poseyendo el extenso Rincón formado por el Río Tacuarí y que estaba integrado por 270.000 cuadras. Los grandes estancieros eran asimismo integrantes del alto comercio que tenía como único puerto habilitado de la Banda Oriental el de Montevideo. En tanto miembros del Gremio de Hacendados y el Gremio de Comerciantes "regulaban los precios de las compras y las ventas, obteniendo por ese medio, el monopolio de la producción de la campaña y de su colocación en los mercados extranjeros” (Beraza, 1969).

Z Alcalde de primer voto: José Vera y Perdomo; alcalde de segundo voto: José Fernández Medina; alguacil mayor: C. Cayetano de Herrera; alférez real: Juan Camejo Soto; fiel ejecutor: Isidro Pérez Rojas; depositario general: Jorge Burgues; síndico procurador general: José González de Melo; alcalde de la santa hermandad: Juan Antonio Artigas; alcalde provincial: Bernardo Gaitán.

$\underline{8}$ AA-CNAA. Primera sección, documento 3, tomo 1, Montevideo, impresores A. Monteverde y Cía., MCML, pp. 8-12.

$\underline{9}$ La importancia de los acontecimientos ocurridos el 24/12/1726 llevó en 1919 a los historiadores del Instituto Histórico y Geográfico del Uruguay a tomar esa fecha como la de fundación “orgánica” de Montevideo, y en 1926 hicieron saber al Concejo de Administración Departamental de Montevideo que se cumpliría ese día el bicentenario de la ciudad.

10 A veces hubo confusión sobre las competencias de los alcaldes y límites de las jurisdicciones en que actuaban. Archivo General de la Nación-Ex Archivo General Administrativo (AGN-EAGA), caja 140, carpeta 3. Borrador de un oficio del Cabildo al gobernador Joaquín del Pino en que le pide ordene a los alcaldes de Nuestra Señora de Guadalupe y de San Juan Bautista (Santa Lucía) no ejerzan actos de jurisdicción en asuntos que competen a los de Montevideo, 15/5/1785. También: AGN-EAGA, caja 140, carpeta 3. Otro borrador de un oficio del Cabildo al gobernador sobre el mismo tema de fecha 8/6/1785.

11 El 12/9/1788 el gobernador de Montevideo, Joaquín del Pino, comunicó al Cabildo que el virrey había resuelto, el 4 del mismo mes, la ampliación de su jurisdicción a los territorios de la Colonia del Sacramento, Real de San Carlos, Rosario, Víboras, Vacas, Santo Domingo de Soriano, Maldonado, pueblo nuevo de San Carlos (cerca de Maldonado), Santa Teresa y Santa Tecla. De este 
modo, el virrey tendía a mantener bajo mando del gobernador territorios que hasta entonces habían estado en poder lusitano (como el Colonia del Sacramento) o bajo guardias españolas sometidas directamente a la obediencia de gobernadores y virreyes del Plata.

12 AGN-EAGA, caja 1 A. Lo que se hizo en conformidad con las leyes 13 y 14, título 5 del libro IV de la Recopilación...

13 Esta obra contiene datos relevantes acerca de los cultivos preferidos y las formas de producción agrícola desarrolladas en los campos de la jurisdicción montevideana. Aunque el texto fue escrito en 1813, y publicado por primera vez en 1848, su contenido recoge las observaciones que el autor hiciera sobre el tema en su chacra del Miguelete durante cuarenta años. Uno de los primeros trabajos históricos sobre el tema es el de Mariano B. Berro. Más recientemente, y con el instrumental del historiador profesional, Jorge Gelman analizó la agricultura en el suroeste de la Banda Oriental subrayando el hecho que las transformaciones acontecidas en las estancias orientadas hacia los mercados no se dieron "en el vacío, como se consideraba hasta hace poco a la campaña rioplatense colonial, sino en un medio ampliamente dominado por la pequeña explotación campesina” (Gelman, 1998, p. 11).

14 Hacia fines del siglo XVIII se encontraban dos sectores diferenciados: por un lado, los propietarios de chacras en el Miguelete o poseedores de tierras de propios, quienes, enriquecidos por la estancia ganadera, pudieron invertir en árboles frutales. También se contaba entre ellos a importantes estancieros que invirtieron parte de su reciente fortuna en la adquisición de chacras para levantar en ellas residencias de descanso trabajadas por mano de obra esclava y/o asalariada. Por otro lado, había agricultores en las inmediaciones de Colonia, Espinillo, Soriano, San José, Canelones, San Juan Bautista entre otros lugares, dedicados a surtir los mercados locales y capaces de introducir en Montevideo trigos y harinas. Quienes entre ellos hicieron fortuna lo lograron a través del comercio: “Comerciantes, algunos labradores más o menos enriquecidos y hacendados de las proximidades formaron la oligarquía lugareña que integró los Cabildos o Medio Cabildos locales” (de la Torre y Sala de Touron y Rodríguez, 1967, p. 132). Agregan los autores que estas "clases dirigentes de los pueblos o villas en nombre de los labradores, enfrentaron a los estancieros y latifundistas cuyos campos rodeaban los centros poblados y que casi siempre estaban en conflicto con ellos”. Esto no impidió por otra parte, que también intentaran conseguir campos para la ganadería. Del primer grupo, el más enriquecido e influyente, los autores citan los casos de Magariños, Maciel, Aguirre-Viana, Suárez, Juanicó, Chopitea, Berro, Tejada, Durán, Pérez, Ortega, García de Zúñiga, Vidal, Sáenz de Cavia y Pereira, muchos de ellos con empleos en el Cabildo montevideano en distintos momentos de su historia.

15 AGN-EAGA, caja 1, carpeta 43. Índice de 20/12/1729 en el que consta acuerdo del 30/1/1730 sobre los días de tabla en que el Cabildo “deverá asistir a la iglesia”; el de 5/4/1730 fue sobre el recibimiento del Real estandarte.

16 AGN-EAGA, caja 295, carpeta 2 A. Certificado (copia) otorgado por el Cabildo sobre las disposiciones que rigen los días de tabla y concurrencia en cuerpo capitular a la iglesia Matriz, 9/8/1805.

17 Con los años, la población se fue extendiendo hacia el oeste, superando un perímetro dividido en 
32 “cuadras” de 100 varas por lado para una población de 250 habitantes, exceptuando la guarnición y los indígenas que trabajaban en las construcciones militares. En 1778 el Cabildo resolvió dar nuevos nombres a las calles tomándolos del santoral: San José (Guaraní), Santo Tomás (calle Maciel), San Vicente (calle Pérez Castellano), San Benito (Colón), San Agustín (calle Alzáibar), Santiago (calle Solís), San Diego (Washington), San Francisco (calle Zabala), San Felipe (Misiones), San Joaquín (Treinta y Tres), San Juan (Ituzaingó), San Fernando (Juan Carlos Gómez), San Telmo (Bartolomé Mitre), San Miguel (Piedras), San Luis (calle Cerrito), San Pedro (calle 25 de Mayo), San Gabriel (Rincón), San Carlos (Sarandí), San Sebastián (calle Buenos Aires) y San Ramón (calle Reconquista). Las calles de Montevideo tenían 12 varas de ancho, es decir, algo más de 10, 5 metros, y a fines del XVIII el Cabildo resolvió que las veredas de las calles comunes tuvieran un ancho de siete cuartas de vara, es decir, un metro y medio aproximadamente, en tanto las de la plaza mayor fueran de tres varas (dos metros y medio). Estas últimas estaban construidas con piedra labrada o ladrillo contando con postes de palo para proteger las calzadas del tránsito de los carruajes. Por carecer de pavimento, hasta fines del siglo XVIII la lluvia transformaba las calles en lodazales, siendo frecuente además la formación de zanjones. El Cabildo intentó resolver este problema acordando en abril de 1770 el arreglo de las calles, costeando el emprendimiento de su cuenta. El Cabildo y testigos de la época (como el sacerdote Pérez Castellano), confirman que los cambios arquitectónicos eran notables en los últimos diez años del siglo XVIII (Reyes Abadie y Vázquez Romero, 1984).

18 Había dos caminos principales que comunicaban el recinto fortificado con los campos de extramuros. Por el portón de San Pedro, o "Viejo" — ubicado en la cortina existente entre la ciudadela y el Cubo del Norte- se daba paso al camino de la "aguada”, que conducía por la fuente denominada del "portón viejo" y bordeando la bahía llegaba hasta la "fuente de Canarias". Este camino junto a otro que rodeaba la ciudadela fueron los más transitados por vecinos y aguateros. El segundo camino era el de San Juan o “nuevo”, ubicado entre la ciudadela y el Cubo del Sur. El camino de San Juan partía del portón homónimo y se dividía en dos caminos: el que iba por la costa y corría paralelo a la ribera sur uniendo las murallas con las playas denominadas de la "estanzuela" y de "Santa Ana” (en las cercanías de la actual Playa Ramírez); el otro camino era el "Maldonado" que corría hacia la parte alta de la cuchilla pasando frente a la guardia del Cordón (siguiendo por la actual Avenida 18 de Julio). Estos dos caminos eran preferentemente transitados por carretas que venían de las chacras y los campos de la campaña. Entraban por el portón de San Juan los cueros y otros artículos de importancia tales como el trigo o la harina (Pérez Montero, 1942 y 1964).

19 Así lo describe el Cabildo en oficio al gobernador del Pino, en el que recuerda cómo se construyó el "templo viejo", y le solicita gestionar fondos ante la Real Hacienda para emprender la nueva obra de la iglesia. AGN-EAGA, caja 155, carpeta 2. Borrador de un oficio del Cabildo sobre cooperación para construir la iglesia Matriz, 1/7/1787.

$\underline{20}$ El gobernador del Río de la Plata Miguel de Salcedo autorizó al Cabildo a trasladar las imágenes de los Santos Patronos a la nueva iglesia el 9/5/1740, luego que el Ayuntamiento se lo pidiera el 23/4/1740, por haber finalizado las obras de construcción. AGN-EAGA, caja 1-2, carpeta 29, 1 fs.

21 Donde hoy se encuentra el edificio del Ministerio de Transportes y Obras Públicas (calle Ituzaingó esquina Rincón), hubo en el siglo XVIII un conjunto de edificios al que llamaban 
"Residencia de san Estanislao de Kostka”, en honor al jesuita que fuera canonizado por el papa Benedicto XIII en 1746. El edificio tenía tres sectores: la capilla, las habitaciones de los padres y los patios y locales para escuela. En 1749 adquirieron un terreno frente a la plaza mayor en el que ampliaron su residencia. A partir de su expulsión en 1767 las edificaciones tuvieron varios destinos: escuela de primeras letras, hospital de tropa, cuartel e incluso sirvieron de almacén de artillería. Con la demolición de la primera iglesia Matriz, la capilla de los jesuitas se utilizó de 1787 a 1804, como Matriz “interina”, hasta que concluyeron las obras de la nueva iglesia principal de la ciudad. En 1809, el inmueble fue dividido en lotes y vendido en subasta pública (Menck Freire y Varese, 1996, p. 214).

22 AGN-EAGA, caja 161, carpeta 4. El 12/6/1788 el cura vicario Juan José Ortiz informó al Cabildo el estado de la iglesia y pidió que dispusiera dónde se debía celebrar misa y colocar el santísimo sacramento. AGN-EAGA, caja 161, carpeta 2. Borrador de un oficio del Cabildo al gobernador del Pino sobre la demolición de paredes de la iglesia Matriz que amenazan su ruina, 2/7/1788.

$\underline{23}$ Esa primera Matriz tuvo concedido por Real cédula el derecho de asilo. AGN-EAGA, caja 37, carpeta 4, 4 fs. Oficio del cura vicario Felipe de Ortega y Esquivel al Cabildo comunicando y adjuntando copia de la Real cédula, 9/7/1774.

$\underline{24}$ El Cabildo era insolvente porque, entre otras cosas, en señal de privilegio Zabala había librado a los primeros pobladores de todo tipo de impuesto. El gobierno de Buenos Aires por su parte prohibió a Montevideo el ejercicio del comercio, argumentando que se trataba de un fuerteguarnición. Sin rentas suficientes, el Ayuntamiento apenas tuvo dinero para pagar al escribiente que redactaba las actas, y pudo recién crear el cargo de secretario de la Corporación el primero de enero de 1756, cuando la institución ya tenía veintiséis años de existencia (Bresciano, 1977, p. 8).

$\underline{25}$ Aliados charrúas y minuanes atacaron en 1701 la estancia misionera del Yapeyú y sus poblaciones a lo que siguió la expedición que les reprimió brutalmente en la batalla del Yí en 1702, dándose la orden de "pasar a degüello" a todos los prisioneros indígenas incluyendo mujeres y niños. (Palermo, 2001, p. 38). Entre 1730 y 1749 atacaron varias veces las poblaciones de Santo Domingo de Soriano, San Salvador y Víboras arreando ganado e incendiando las plantaciones; los charrúas atacaron la Colonia del Sacramento en 1769 y juntos, charrúas y minuanes derrotaron a las tropas de las Misiones en 1798.

$\underline{26}$ Lo que no significó que terminara la lucha. En el acta de 1764 acordó el Cabildo levantar una guardia en la frontera de la jurisdicción para sostener a los vecinos contra la rebelión de los “enemigos los Indios Infieles dela nación Minuana que se han retirado a la campaña”. AGN-EAGA. Actas del Cabildo de Montevideo. De 6/9/1763 a 26/9/1768, tomo 4, libro 9. Acta de 3/9/1764, f. 78.

$\underline{27}$ Estos fueron: Francisco A. de Lemos, Francisco de Cárdenas, N. Carbajal, Fructuoso de Palafox, Alonso de la Vega, José de Arce y Soria, Francisco Lobato, Domingo Santos de Uriarte y Francisco Gorriti.

$\underline{28}$ El primer “cañonazo” se daba cuando despuntaban las primeras luces del día, momento en que el mayor de la Plaza salía del Fuerte y con las llaves en la mano abría una pequeña puerta del portón 
que sólo permitía el acceso a la ciudad a quienes se hallaban a pie. A la salida del sol y con el segundo disparo se abría el portón propiamente dicho y luego, a la puesta del sol, se procedía a cerrar el gran portón, quedando la ciudad comunicada por tierra sólo a través de una pequeña puerta custodiada por centinelas. A las ocho de la noche, con el último disparo de cañón, también se cerraba esta puerta.

$\underline{29}$ En informe a Felipe V sobre el memorial presentado por José García Inclán, el teniente de rey de Buenos Aires, Baltasar García, había propuesto el 31/8/1721, no sólo el establecimiento de una población en la ensenada de la ulterior Montevideo sino que, en consideración de la resistencia indígena, era conveniente que la monarquía nombrara gobernador para el lugar. Revista Histórica, tomo V, $4^{\circ}$ trimestre de 1912, n 15, Montevideo, Archivo y Museo Histórico Nacional, pp. 118-144.

$\underline{30}$ Con diecisiete años de edad, Juan de Achucarro desembarcó en Montevideo en 1727 conducido por su primo, el naviero y jefe de la expedición colonizadora don Francisco de Alzáibar. En 1744, Achucarro - por entonces alcalde de segundo voto - fue nombrado representante del Ayuntamiento ante el gobernador de Buenos Aires, José de Andonaegui, con el propósito de gestionar ante él "la separación de los poderes municipal y militar”. Los Zabala de Durango, los Alzaíbar de Lémona y los Achucarro de Galdácano "procedían de casa solariegas vizcaínas cuya inmediación inmemorial había creado vínculos estrechos entre sus respectivos vástagos” (Azarola Gil, p. 42).

31 AGN-EAGA, caja 2, carpeta 24, 2 fs. El gobernador Andonaegui aceptó su dimisión el 8/5/1750 en el contexto de guerra con los minuanes y próximo arribo del gobernador de Montevideo Joaquín de Viana.

32 AGN-EAGA, caja 9, carpeta 6, 34 fs. Copia testimoniada del título y nombramiento de 4/4/1757.

$\underline{33}$ Tras el fin de la Guerra de Sucesión uno de los nuevos “centros de la trama de fidelidades” al rey fueron los Cuerpos de Guardias de Corps, de Regimientos Reales de Infantería y las Guardias Walonas, en suma, el estamento militar. La Monarquía les prefirió llegado el momento de nombrar autoridades para el Río de la Plata, pues compartían el hecho de haber "tenido una carrera militar importante, y todos formaban parte de las nuevas élites llegadas a las estructuras de la corte”. Ejemplo de ello es la designación del propio Bruno Mauricio de Zabala y su sucesor Miguel Fernando de Salcedo y Sierralta.

$\underline{34}$ Teniendo a la vista las cifras de los documentos del periodo hispánico, Reyes Abadie y Vázquez Romero señalaron que, sin perjuicio de admitir salvedades sobre ellas, la población de Montevideo aumentó notablemente en la segunda mitad del siglo XVIII. Para 1760 estimaban la población total (casco, alrededores y jurisdicción) en 2.089 personas y para 1778 en 9.602, para 1787 en 12.382 y en 1801 de 15.245, cifra formada por 8.500 personas en el recinto propiamente dicho y 6.245 en los alrededores y resto de la jurisdicción. En diciembre de 1805 el subteniente Nicolás de Vedia realizó un padrón para el casco edificado en el que distinguió de un total de 9.359 habitantes: 5.915 "blancos”, 578 "pardos, indios naturales y negros libres” y 2.866 esclavos (Reyes Abadie y Vázquez Romero, 1984, p. 454).

35 AGN-EAGA, caja 97, carpeta 4, 17/5/1780.

36 Elevada Montevideo a la categoría de Plaza de Armas y Gobierno político militar en 1750 se 
prohibió construir casas de material hasta la distancia de un tiro de cañón (600 toesas, es decir, unos 1.200 metros) fuera de los portones de San Pedro y San Juan. El área en la que no podía levantarse construcción alguna de forma permanente fue delimitada por una línea que comenzaba en el sitio llamado Piedra Grande (ubicado en el medio de la actual calle Tacuarembó, entre Galicia y Cerro Largo, pasando a metros del lado este de la plazoleta del Gaucho y terminando a la altura de la esquina formada por las actuales calles Vázquez y Gonzalo Ramírez, frente a la playa).

\section{Bibliografía}

Acosta y Lara, E. (1989). La Guerra de los Charrúas en la Banda Oriental. Montevideo: Linardi y Risso.

Aguerre Core, F. (2012). Los últimos españoles. Autonomía y lealtad a la Corona en el Montevideo insurgente (1802-1815). Montevideo: Linardi y Risso.

Arteaga, J. J. (1999). Las Consecuencias del Tratado de Madrid en la desarticulación de la frontera demográfica de la Banda Oriental, 1750-1761. Montevideo: Ministerio de Educación y Cultura, Archivo General de la Nación.

Apolant, J. A. (1975). Génesis de la familia uruguaya. Los habitantes de Montevideo en sus primeros 40 años. Filiaciones, ascendencias, entronques, descendencias. Montevideo, s/d, tomo 1.

Assunçao, F. O. y Bombet Franco, I. (1990). La ciudad vieja. Montevideo: Fundación Banco de Boston.

Azarola Gil, L. E. (s/d). Contribución a la Historia de Montevideo. Veinte linajes del siglo XVIII. París: Casa Editorial Iberoamericana.

Baroffio Burastero, R. (1994). El rescate de las murallas de Montevideo. Apartado del Boletín Histórico del Ejército, No 287-290.

Barrán, J. P. (2008). Historia de la sensibilidad en el Uruguay. Montevideo: Banda Oriental.

Barriera, D. G. (2006). Economía y Sociedad (Siglos XVI a XVIII), tomo 3. Rosario: Prohistoria ediciones-Diario La Capital.

Barriera, D. G. (2013). Abrir puertas a la tierra. Microanálisis de la construcción de un espacio político. Santa Fe, 1573-1640. Rosario: Museo Histórico Provincial de Santa Fe.

Barrios Pintos, A. (1973). Historia de la ganadería en el Uruguay, 1573-1973. Montevideo: Biblioteca Nacional.

Bauzá, F. (1965). Historia de la dominación española en el Uruguay. Montevideo: Colección de Clásicos Uruguayos, vol. 97, tomo III.

Beraza, A. (1969). La economía de la Banda Oriental 1811-1820. Montevideo: Banda Oriental.

Berro, M. B. (1914). La agricultura colonial. Montevideo: Imprenta Artística Juan J. Dornaleche.

Blanco Acevedo, P. (1959). El gobierno colonial en el Uruguay y los orígenes de la nacionalidad. 
Montevideo: Impresora LIGU S.A.

Bracco, D. (2004). Charrúas, guenoas y guaraníes: interacción y destrucción. Montevideo: Linardi y Risso.

Bresciano, R. H. (1977). El Cabildo de Montevideo. Montevideo: Intendencia Municipal de Montevideo.

Capillas de Castellanos, A. (1971). Montevideo en el siglo XVIII. Montevideo: Nuestra Tierra.

de la Torre, N., Sala de Touron, L. y Rodríguez, J. (1967). Estructura económico-social de la Colonia. Montevideo: Pueblos Unidos.

de la Torre, N., Sala de Touron, L. y Rodríguez, J. (1967). Artigas: tierra y revolución. Montevideo: Arca editorial.

de María, I. (2005). Montevideo Antiguo. Tradiciones y recuerdos. Montevideo: Banda Oriental.

Enciso, L. M. (2001). La Europa del siglo XVIII. Barcelona: editorial Península.

Fucé, P. (2003). Cerca de la horca. Historia de Colonia del Sacramento a partir de una causa criminal. Montevideo: Torre del Vigía editorial.

Fucé, P. (2014). El poder de lo efímero. Historia del ceremonial español en Montevideo (17301808). Montevideo: Linardi y Risso editores.

Gelman, J. (1998). Campesinos y estancieros. Una región del Río de la Plata a fines de la época colonial. Buenos Aires: Los Libros del Riel.

Jumar, F. (2010). Le commerce atlantique au Río de la Plata, 1680-1778. La Plata.

Martínez Montero, H. (1977). Montevideo nació en el mar. Montevideo: Centro de Estudios Navales y Marítimos.

Melogno, T. (1968). Portugos y brasileños. Historia ilustrada de la civilización uruguaya, 1(6).

Menck Freire, C. y Varese, J. A. (1996). Viaje al antiguo Montevideo. Retrospectiva gráficotestimonial. Montevideo: Linardi y Risso editores.

Millot, J. y Bertino, M. (1991). Historia económica del Uruguay. Montevideo: Fundación de Cultura Universitaria, tomo 1.

Pérez Castellano, J. M. (1968). Observaciones sobre agricultura Montevideo: Biblioteca Artigas, Colección de Clásicos Uruguayos, volumen 131, tomo I.

Palermo, E. (2001). Banda Norte: Una Historia de la Frontera Oriental. Rivera, s/d.

Pérez Montero, C. (1942). La calle del 18 de julio (1719-1875). Antecedentes para la historia de la ciudad nueva. Montevideo: Imprenta El Siglo Ilustrado.

Pérez Montero, C. (1964). Los aledaños de Montevideo en 1811, AAVV. La Revolución de 1811 en la Banda Oriental. Montevideo: Junta Departamental de Montevideo.

Petit Muñoz, E., Narancio, E. M. y Traibel Nelcis, J. M. (1947). La condición jurídica, social, 
económica y política de los negros durante el coloniaje en la Banda Oriental. Vol. 1. (Primera parte). Montevideo: Publicaciones oficiales de la Facultad de Derecho y Ciencias Sociales.

Pivel Devoto, J. E. (1946). Raíces coloniales de la Revolución Oriental de 1811. Montevideo: Medina.

Rama, Á. (1998). La ciudad letrada. Montevideo: Arca.

Real de Azúa, C. (1961). El patriciado uruguayo. Montevideo: Asir.

Reyes Abadie, W. y Vazquez Romero, A. (1984). Crónica General del Uruguay. Montevideo: Banda Oriental.

Reyes Abadie, W., Bruschera, W., y Melogno, T. (1974). La Banda Oriental: pradera, frontera, puerto. Montevideo: Banda Oriental.

Ribeiro, A. (2013). Los muy fieles: leales a la corona en el proceso revolucionario rioplatense: Montevideo-Asunción, 1810-1820: estudio comparado. Montevideo: Planeta.

Rial, J. y Klaczko, J. (1981). Uruguay: el país urbano. Montevideo: Banda Oriental.

Tellez Alarcia, D. (2006). La manzana de la discordia. Historia de la Colonia del Sacramento desde la fundación portuguesa hasta la conquista definitiva por los españoles. Montevideo: Torre del Vigía.

Travieso, C. (1923). “iMontem Vídeo!” Origen del nombre de Montevideo. Montevideo: Imprenta Latina,

Tuñón de Lara, M. (dir.) (1980). Historia de España VII. Centralismo, Ilustración y agonía del Antiguo Régimen (1715-1833). Barcelona: Editorial Labor. 